\title{
A Review on Diagnostic and Prognostic Techniques Employed During Bovine Uterine Torsion
}

\section{Ankur Abrol, Madhumeet Singh, Akshay Sharma* and Pravesh Kumar}

Department of Veterinary Gynaecology and Obstetrics, Dr. G. C. Negi College of Veterinary and Animal Sciences, CSKHPKV, Palampur, 176062 India.

\begin{abstract}
Dystocia, an obstetrical emergency handled by veterinarians, is one of the important issues of dairy industry which lays a considerable impact on farmers economically. From a clinical frame of reference, the etiology of dystocia is either of maternal or fetal origin although the exact etiology is multifaceted. Uterine torsion is considered as one of major contributors among the maternal causes. This condition exerts considerable stress on the animal and if not treated promptly, it can lead to deterioration of liver and kidney functions resulting in toxaemia followed by dam as well as fetal mortality. So, the most important aspect in successful management of uterine torsion lies in the correct and efficient diagnosis which can mainly be achieved by anamnesis, vaginal and rectal examination. However, prognosis of uterine torsion is mainly dependent on the degree and duration of condition and can be categorised into 3 successive stages i.e. stage of positive prognosis, stage of less positive prognosis and stage of negative prognosis. Body condition assessment of the dam is of paramount importance as it can provide a snapshot about the possible prognosis of the animal diagnosed with uterine torsion.

Editor | Muhammad Abubakar, National Veterinary Laboratories, Park Road, Islamabad, Pakistan

Received | September 18, 2019; Accepted | November 14, 2019; Published | December 10, 2019

*Correspondence | Akshay Sharma, Department of Veterinary Gynaecology and Obstetrics, Dr. G.C. Negi College of Veterinary and Animal Sciences, CSKHPKV, Palampur, 176062 India; Email: akshays482@gmail.com

Citation | Abrol, A., M. Singh, A. Sharma and P. Kumar. 2020. A review on diagnostic and prognostic techniques employed during bovine uterine torsion. Veterinary Sciences: Research and Reviews, 6(1): 7-13.

DOI | http://dx.doi.org/10.17582/journal.vsrr/2020/6.1.7.13

Keywords | Bovines, Diagnosis, Middle uterine artery, Prognosis, Uterine torsion
\end{abstract}

\section{Introduction}

$\mathrm{L}$ ivestock is a major player in the Indian rural economy as the biggest chunk of livestock farming is shared by bovines i.e. cattle and buffaloes. The key to a successful dairy farming venture lies in the efficacy of reproduction which includes the culmination of pregnancy via normal calving process. Calving is an extremely critical phase and any difficulty in smooth ensuing of calving, known as dystocia, puts massive stress on the animal physiologically as well as on the farmer monetarily (Funnell and Hilton, 2016). Dystocia, however is a multifaceted problem and is generally classified into being of maternal or fetal origin (Abera, 2017). Amongst the maternal causes of dystocia in bovines, uterine torsion is the most commonly encountered cause of maternal dystocia (Sharma et al., 2018). Uterine torsion in its literal terms means twisting of the gravid uterus on its longitudinal axis (Purohit et al., 2011). The condition being of grave emergency demands immediate attention as delay in managing the case might lead to further complications like delayed uterine involution, dwindled future reproductive performance and rapid mortality of the animal (Amin et al., 2011; Uttam et al., 2015). Primary risk factors for the occurrence of uterine torsion are excessive fetal movement during first stage of calving as the fetus adopts the birth posture January-June 2020 | Volume 6 | Issue 1 | Page 7 
and increased uterine instability at term (Noakes, 2009). Uterine torsion is considered to be the single largest condition contributing to dystocia in bovines with incidence as high as $56-80$ per cent (Srinivas et al., 2007). The key to successful management of uterine torsion cases lies in efficient diagnosis and with the advancement of research various prognostic parameters have also been envisaged which serve as an aid in successful management of the condition (Ghuman, 2010).

\section{Diagnosis of uterine torsion}

The most important aspect in successful management of uterine torsion lies in the correct and efficient diagnosis of uterine torsion (Purohit et al., 2011). The standardised methods for diagnosis have always relied upon set of 3 procedures to diagnose the condition viz., Anamnesis, vaginal and rectal examination while a few newer novel diagnostic aids have also been devised to aid the already existing methods of diagnosis i.e. finger side test, forearm entrance test and cranial displacement of middle uterine artery from its normal anatomical position (Thangamani et al., 2018b).

\section{Anamnesis}

Anamnesis plays a key role in diagnosis of uterine torsion and failure in progression of calving (Ghuman, 2010) accompanied by other signs such as colic symptoms, frequent lying down and getting up of the animal as a result of pain (Ali et al., 2011). Certain external signs evident during uterine torsion are vulvar commissure displacement, sinking of lumbosacral spine along with elevated tail head (Lyons et al.,2013). Failure to correct the condition in initial stages usually leads to resorption of fully developed udder along with stretching of pelvic ligaments along with tachypnoea and tachycardia (Deosi and Dhaliwal, 2015).

\section{Vaginal and rectal examination}

Vaginal examination is primarily of use in diagnosis of post-cervical uterine torsion by palpating the stenosed anterior vagina (Jeengar, 2013) though rectal examination is considered as a gold standard in diagnosis of pre-cervical uterine torsion as broad ligament can be felt as a tight band running towards opposite direction to that of uterine torsion (Bai et al., 2016). Ascertaining the degree of uterine torsion is also a very critical step as uterine torsion of increased degree has been found to be correlated with negative prognosis and thus, the treatment regimen to be adopted is also based on taking into consideration the degree of condition (Srinivasarao, 2016). The degree of uterine torsion is mainly assessed by the status of cervix accessibility as the degree of uterine torsion exceeds, the cervical accessibility also diminishes accordingly (Purohit and Gaur, 2014). Uterine torsion has been classically categorised into mild, moderate and severe degree (Naidu et al., 2014) and most commonly encountered uterine torsion falls into moderate degree (Srinivas et al., 2007).

\section{Newer diagnostic aids}

Though the conventional methods still continue to be the gold standard in diagnosing uterine torsion and differentiating the condition from other medicosurgical conditions like tympany, intussusception, vagal indigestion and colic (Purohit et al., 2013) but still over the years a few novel methods have also been devised to aid the conventional techniques. These novel methods include tests such as forearm entrance test, finger side test and cranial displacement of middle uterine artery from its normal anatomical location (Thangamani et al., 2018b). Forearm entrance test implies that only one fourth of forearm passes in the vagina during uterine torsion as compared to three fourth in advanced gestational bovine while the finger test implies the principle that the fingers go to the left side through the vaginal folds and dorsal face of the fore arm faced on right side indicating right side torsion and vice versa for left side uterine torsion (Thangamani et al., 2018b).

\section{Prognostic indicators of uterine torsion}

The main determinants of prognosis of uterine torsion are the degree and duration of condition, as the cut off duration for better prognosis has been established as 36 hours (Jeengar et al., 2015). The stage of prognosis in uterine torsion cases has been categorised into 3 successive stages i.e. stage of positive prognosis, stage of less positive prognosis and stage of negative prognosis (Ghuman, 2010). Assessing the body condition of the dam is always of paramount importance as it can provide a snapshot about the possible prognosis of the case presented and hence, these points must always be given due consideration while deciding the treatment protocol (Joshi et al., 2018).

Parturition is a stressful event in the life of an animal as evinced by changes in certain haematological and biochemical parameters (Joshi et al., 2018). Uterine torsion being an even more stressful condition

January-June 2020 | Volume 6 | Issue 1 | Page 8 
exerts even more stress on the body of bovine and there is massive alteration in the haematological and biochemical values as they continue to vary from case to case depending upon degree and duration of the condition (Tripathi and Mehta, 2016). Certain new techniques like Doppler sonography of middle uterine artery in addition to haemato-biochemical estimations have been very useful in acting as prognostic indicators of uterine torsion affected animals (Thangamani et al., 2018a).

\section{Haematological alterations}

Uterine torsion affected bovines reveal profound changes in their haematological picture which is characterised by normocytic normochromic anaemia and neutropaenia along with leucopaenia due to endotoxaemic condition (Amer et al., 2008). The reason attributed to normocytic normochromic anaemia was accumulation of large amount of metabolic waste or massive haemorrhages which usually occur following uterine torsion (Amer and Hashem, 2008). The duration of condition also lays a considerable impact on the haematological parameters as prolonged duration of the condition leads to corresponding decrease in haemoglobin and mean cell haemoglobin concentration coupled with an increase in total leucocyte count, neutrophilia and lymphopaenia (Dhindsa et al., 2005). The reason for these changes has been found to be related with the activation of adrenal gland as a consequence of stress thereby causing increased mobilisation of neutrophils in blood stream. The increase in neutrophils as sequelae of uterine torsion has been imputed to occur due to increase in cortisol levels which further decreases neutrophil superoxide production and subsequently, phagocytosis of neutrophils (Brown et al., 2008). In normal advanced gestation bovines owing to increased maternal erythropoietin production, there is increase in total erythrocyte count (TEC) along with haemoglobin concentration (Chandra et al., 2012; Mohamed et al., 2015) but in uterine torsion affected bovines owing to the massive haemorrhages, there is reduction in the TEC and haemoglobin. In animals which fail to yield a satisfactory response to maneuver, it was reported that Red blood cells fail to get stabilised after detorsion and continue to remain fragile and liable to breakdown (Thangamani et al., 2018a).

Biochemical and hormonal alterations

Being an extremely stressful condition, uterine torsion leads torsion leads to changes in biochemical as well as endocrinological parameters (Ghuman, 2010). In addition to haemato-biochemical changes, uterine torsion induces massive oxidative stress at tissue level due to increased production of free radicals as discernible by the high levels of malondialdehyde, superoxide dismutase and glutathione. These levels provide a very accurate estimate of cellular and tissue damage, thereby aiding in instituting a better treatment protocol for a favourable prognosis (Bansal et al., 2011).

Uterine torsion also puts effect over hepatic and renal system as reflected by the changes in the levels of liver specific enzymes, glucose and renal function tests (Amer et al., 2008). Therefore, the extent of damage and hence the prognosis of each case could be readily analysed by liver and kidney function tests (Tripathi and Mehta, 2016). Uterine torsion leads to catecholamine release via activation of stress axis characterised by an increase in cortisol and superoxide dismutase levels (Khan, 2012). This leads to hypoperfusion of the kidneys thereby leading to failure of the kidneys to excrete out creatinine and subsequently results in creatinine buildup along with other toxic products (Yadav et al., 2015). Similarly, an increase in level of total bilirubin and blood urea nitrogen along with decreased total protein level is also a prognostic indicator of uterine torsion (Srinivasarao, 2016).

As far as endocrinological profile of uterine torsion affectedbovinesisconcerned,a reverse endocrinological picture to that of normally calving bovineshas been observed (Ghuman, 2010). Coupled with the alterations in the haemato-biochemical parameters, the malady also showcases its effect on the mineral status of the animal (Singh et al., 2009). Amongst the trace minerals, zinc is the most crucial mineral involved in parturition and its altered concentration makes the animal prone to calving problems (Khan, 2012). Hyperglycemia is a consistent feature of fresh uterine torsion cases as activation of stress axis leads to increased gluconeogenesis (Ghuman, 2010) while with the increase in the chronicity of the condition; there is gradual hypoglycaemia (Srinivasarao, 2016). Increase in the blood lactate levels can act as a prognostic indicator of tissue, thereby helping in arriving at prognosis of the case (Murakami et al., 2017).

Blood histamine levels are very useful prognostic markers as they give an overall picture regarding the 
extent of tissue damage as there is a subsequent release of histamine (Mehra et al., 2018). Besides these, certain other markers such as plasma haptoglobin which is an acute phase protein released as a result of inflammatory process (Ghuman et al., 2009) and creatine kinase which is indicative of the muscle damage can also be used as prognostic indicators (Amin et al., 2011). Amongst the electrolytes, lowered magnesium concentration has been found to be correlated with poor prognosis of the case as magnesium is a cofactor of many enzymes involved in the tissue repair (Rukgauer, 2005).

\section{Doppler sonography of middle uterine artery}

Trans-rectal Doppler sonography being a comparatively less invasive method of assessing the haemodynamic status has generated a keen interest among researchers (Bollwein et al., 2016). Various semi-quantitative indices such as resistance index, pulsatility index, time average maximum velocity, time average mean velocity and blood flow volume have been established to quantitatively establish the perfusion status of various organs and they are relative quantities which measure the resistance encountered by blood flow (Bollwein et al., 2002). Since these indices depict the resistance to the blood flow, hence they can be used as a prognostic indicator in case of uterine torsion (Ratta et al., 2016). Resistance index (RI) also known as Pourcelot's ratio is an indicator of tissue perfusion during the diastole (Ratta et al., 2016) while pulsatility index (PI) measures the resistance offered to the blood flow due to vascular bed constriction with the point of measurement being distal in position (Elmetwally, 2012).

Doppler sonography can also be used to differentiate fetal viability status by assessing the fetal heart rate at various stages of the pregnancy (Jonker et al., 2014). Doppler sonography of the middle uterine artery can be used in determining the degree, duration as well as prognosis of uterine torsion cases both in dam as well as fetus. Doppler indices such as RI and PI showed an increase in uterine torsion affected bovines indicative of massive hindrance to the blood flow while there is a corresponding fall in blood flow volume and time average maximum and mean velocities along with the presence of prediastolic notch, thereby indicative of end diastolic flow being negligible in uterine torsion cases (Hussein, 2013). This notch evidently becomes indiscernible at 6 months during normal gestation (Varughese et al.,2013), thereby indicating completion of anatomical and vascular bed completion (Laven and Peter, 2001).

Besides the constriction of blood vessel during uterine torsion, another endocrinological explanation has also been put forth which states that there is lowered estrogen thereby leading to reduction in the vascular perfusion status of the artery (Rawy et al., 2018). With an increase in the duration and degree of uterine torsion, there is also proportionate reduction in the blood flow to the uterus and can be evidently seen by spectral waveforms of middle uterine artery with evident cardiac abnormalities in torsion affected bovines (Schonfelder et al., 2005). Reduction in blood flow gets more pronounced as degree and duration of the condition increases and hence, can act as a prognostic marker (Ratta et al., 2016). In addition to trans-rectal sonography, transabdominal ultrasonography can also act as a very useful prognostic tool in predicting the fate of clinical cases by assessing the changes in echotexture of the uterus as a consequence of inflammatory and necrotic changes in uterine tissue which occur following occurrence of uterine torsion (Devender et al., 2016). Besides aiding in prognosis of uterine torsion cases, Doppler sonography of middle uterine artery and fetal umbilicus can also be very useful in determining the pattern of blood flow throughout the gestation in bovines (Singh et al., 2018).

\section{Conclusions and Recommendations}

Uterine torsion has always generated a keen interest among animal reproduction researchers owing to the mysteries surrounding the occurrence of the condition. Besides the conventional prognostic techniques like haemato-biochemical techniques, certain novel techniques like Doppler sonography have opened new avenues to be explored. In coming times, the studies focused on the genetic aspect of the condition need to be explored to explain and find out that whether the occurrence of the condition is related to some genetic level malady or not as this area has been left totally unexplored as of now.

\section{Authors Contribution}

All the authors have worked in a collaborative way while writing the review. 


\section{Conflict of Interest}

The authors declare no conflict of interest.

\section{References}

- Abdellah, M.R., R.I. Derar and G.A. Megahed. 2014. Blood constituents of buffaloes in response to prognosis and duration of uterine torsion. J. Anim. Vet. Adv. 13: 217-222.

- Abera, D. 2017. Management of dystocia in cattle: A Review. J. Reprod. Infertility 8(1): 1-9.

- Ali, A., R. Derar, H.A. Hussein, A.M.R. Ellah and A.K.A. Razek. 2011. Clinical, hematological, and biochemical findings of uterine torsion in buffaloes (Bubalusbubalis). Anim. Reprod. Sci. 126: 168- 172. https://doi. org/10.1016/j.anireprosci.2011.05.005

- Amer, H.A. and M.A. Hashem. 2008. Relationship between clinical and biochemical picture of uterine torsion in Egyptian buffaloes (Bubalusbubalis). Int. J. Vet. Med. 4(1): 1-11. https://doi.org/10.5580/1157

- Amer, H.A., M.A. Hashem and A. Bader. 2008. Uterine twisting during pregnancy in buffaloes: relationship between clinical findings and biochemical indices. J. Appl. Biol. Sci. 2: 31- 39.

- Amin, S.M., H.A. Amer, A.E. Hussein and A.M. Hazzaa. 2011. Creatine phosphokinase and aspartate amino transverse profiles and its relation to severity of uterine torsion in Egyptian buffalo. Anim. Reprod. Sci. 123(3): 163-168. https://doi.org/10.1016/j. anireprosci.2010.12.002

- Bai, T., T. Diraviyam, Z. Zhou, Z. Jiang and X. Zhang. 2016. A comparative study of two uterine torsion correction methods in parturient cows. Vet. Arch. 86(6): 787-793.

- Bansal, A.K., A.K. Singh, R.S. Cheema, P.S. Brar, V.K. Gandotra, P. Singh and S. Prabhakar. 2011. Status of oxidative stress and antioxidant enzymes in normally calved and dystocia affected buffaloes. Indian J. Anim. Sci. 81(9): 915-918.

- Bleul, U., S. Schwantag and W. Kahn. 2008. Blood gas analysis of bovine fetal capillary blood during stage two of labor. Theriogenol. 69(2): 245-251. https://doi.org/10.1016/j. theriogenology.2007.09.027

- Bollwein, H., U. Baumgartner and R. Stolla. 2002.Transrectal doppler sonography of uterine blood flow in cows during pregnancy. Theriogenol. 57: 2053-2061. https://doi. org/10.1016/S0093-691X(02)00706-9

- Bollwein, H., M. Heppelmann and J. Luttgenau. 2016. Ultrasonographic doppler use for female reproduction management. Vet. Clin. Food Anim. 32(16): 149-164. https://doi. org/10.1016/j.cvfa.2015.09.005

- Brown, A.S., J.D. Levine and P.G. Green. 2008. Sexual dimorphism in the effect of sound stress on neutrophil function. J. Neuroimmunol. 205: 25-31. https://doi.org/10.1016/j. jneuroim.2008.08.005

- Chandra, S., A.K. Tripathi, S. Mishra, M. Amrazul and A.K. Vaish. 2012. Physiological changes in haematological parameters during pregnancy. Indian J. Haematol. Blood Transfus. 28(3): 144-146. https://doi.org/10.1007/ s12288-012-0175-6

- Deosi, H.S. and G.S. Dhaliwal. 2015. Clinical observations as an index for selecting interventional strategies in uterine torsion affected buffaloes. Vet. Alumunus. 36(1): 28-31.

- Devender, R.K. Chandolia, A.K. Pandey, V. Yadav, P. Kumar and J. Dalal. 2016. Transabdominal colordoppler ultrasonography: A relevant approach for assessment of effects of uterine torsion in buffaloes. Vet. World. 9(16): 842-849. https://doi.org/10.14202/ vetworld.2016.842-849

- Dhindsa, S.S., V.K. Gandotra, A.S. Nanda, S.P.S. Singh, R. Jindal and P.S. Brar. 2005. Effect of duration of dystocia on haematobiochemical alterations in buffaloes. Indian J. Anim. Reprod. 26: 117-119.

- Elmetwally, M.A. 2012. Clinical applicability of non-invasive Doppler ultrasonography in small ruminants throughout pregnancy. DVM Thesis. Germany. p.30.

- Funnell, B.J. and W.M. Hilton. 2016. Management and prevention of dystocia. Vet. Clin. North Am. Food Anim. 32(2): 511-522. https://doi.org/10.1016/j.cvfa.2016.01.016

- Ghuman, S.P.S., A. Kumar and M. Honparkhe. 2009. A preliminary study on plasma haptoglobin concentrations in buffaloes following spontaneous or assisted delivery. Buffalo Bull. 28(3): 127-130.

- Ghuman, S.P.S. 2010.Uterine torsion in bovines a review. Indian J. Anim. Sci. 80(4): 289-305.

- Hussein,H.A.2013. Validation of color Doppler 
ultrasonography for evaluating the uterine blood flow and perfusion during late normal pregnancy and uterine torsion in buffaloes. Theriogenol. 79: 1045-1053. https://doi. org/10.1016/j.theriogenology.2013.01.021

- Jeengar, K., G.N. Purohit, J.M. Singh, V. Choudhary and A. Tripathi. 2015. Prognostic tests for uterine torsion affected buffaloes. Theriogenol. Insight. 5(1): 33-40. https://doi. org/10.5958/2277-3371.2015.00003.0

- Jeengar, K. 2013. Studies on incidence, type, prognostic and therapeutic approaches for uterine torsion in buffaloes. M.V.Sc. Thesis, RAJUVAS, Bikaner, India.

- Jonker, F.H., H.A. Oord van, H.P. Geijn van, V.G.C. Weijden and M.A.M. Taverne. 2014. Feasibility of continuous recording of fetal heart rate in the near-term bovine fetus by means of transabdominal Doppler. Vet. Q. 16(3):165168. https://doi.org/10.1080/01652176.1994. 9694442

- Joshi, K.R., M.M. Pathan, S.P. Madhira, A.M. Pande and D.D. Dhusa. 2018. Study of haematological parameters of crossbred cows during peripartumperiod. Int. J. Curr. Microbiol. Appl. Sci. 7(12): 461-467. https:// doi.org/10.20546/ijcmas.2018.712.057

- Khan, S. 2012. Studies on etio-pathology and therapeutics of bovine dystocia in Himachal Pradesh. M.V.Sc. Thesis, Chaudhary Sarwan Kumar Himachal Pradesh Krishi Vishvavidyalaya, Palampur, India.

- Laven, R.A. and A.R. Peters. 2001. Gross morphometry of bovine placentome during gestation. Reprod. Domest. Anim. 36: 289-296. https://doi.org/10.1046/j.14390531.2001.00297.x

- Lyons, N.A., T.J.D. Knight-Jones, B.M. Aldridge and P.J. Gordon. 2013. Incidence, management and outcomes of uterine torsion in UK dairy cows. Cattle Pract. 21: 1-6.

- Mehra, U.S., S.C. Arya, A. Deora, R.P.Diwakar, P. Kumar and R. Yadav. 2018a. Meloxicam administration in dystocia affected bovines and its impact on release of histamine. Int. J. Curr. Microbiol. Appl. Sci. 7(5): 3341-3346. https:// doi.org/10.20546/ijcmas.2018.705.390

- Mohamed, G.A.E., E.M. Abdelnaser and K.E. Hanan. 2015. Preliminary study on lipid profile with relation to total antioxidant capacity and some hematological and biochemical changes of pre-postpartum buffalo heifers at Assiut city. Assiut Vet. Med. J. 61: 159-165.

- Murakami, T., S. Nakao, Y. Sato, S. Nakada, A. Sato, S. Mukai, M. Kobayashi, Y. Yamada and E. Kawakami. 2017. Blood lactate concentration as diagnostic predictors of uterine necrosis and its outcome in dairy cows with uterine torsion. J. Vet. Med. Sci. 79(3): 513-516. https://doi. org/10.1292/jvms.16-0203

- Naidu, G.V., B. Srilatha and B.G. Ravi. 2014. A retrospective study of factors affecting dystocia in Murrahbuffaloes. Intas. Polivet. 15: 279-283.

- Noakes,D.E.2009.Dystocia and other disorders associated with parturition. In: Veterinary Reproduction and Obstetrics (DE Noakes, TJ Parkinson and GCW England, eds.). WB Saunders Company, London. p 209-326.

- Purohit, G.N. and M. Gaur. 2014. Uterine torsion in buffaloes: a critical analysis. Buffalo Bull. 33(4): 363-378.

- Purohit, G.N., Y. Barolia, C. Shekhar and P. Kumar. 2011. Maternal dystocia in cows and buffaloes: A Rev. Open J. Anim. Sci. 1(2): 4153. https://doi.org/10.4236/ojas.2011.12006

- Purohit, G.N., J.S. Mehta, S.C. Shekher, P. Kumar, A. Kumar, S. Raiya, S. Ruhil and M. Gaur. 2013. Uterine torsion in buffaloes: A retrospective analysis of 52 cases. Ruminant Sci. 4(2): 219-222.

- Ratta, N.S., S.S. Ghuman and V.K. Gandotra. 2016. Predicting the impact of degree and duration of uterine torsion on uterine blood supply in cattle using Doppler ultrasonography. J. Anim. Res. 6(4): 685-689. https://doi. org/10.5958/2277-940X.2016.00082.6

- Rawy, M., S. Mido, H.E.S. Ali, D. Derar, G. Megahed, G. Kitahara and T. Osawa. 2018. Effect of exogenous estradiol Benzoate on uterine blood flow in postpartum dairy cows. Anim. Reprod. Sci. 192: 126-145. https://doi. org/10.1016/j.anireprosci.2018.03.001

- Rukgauer, M. 2005. Magnesium: Laboratory and diagnostics, indication and evaluation of laboratory results for medical diagnosis. Theriogenol. Verlagsgesellschaft $6^{\text {th }}$ edn: $492-$ 494.

- Schonfelder, A., A. Richter and A. Sobiraj. 2005. Doppler ultrasound studies of the uterine arteries in cows with spontaneous parturition and with uterine torsion intra partum. Wiener Tierarztl. Monatsschr. 92: 74-80. 
- Sharma, A., M. Singh and N. Bhardwaj. 2018. Maternal dystocia in bovines-an overview. Indian Farmer. 5(04): 443-446

- Singh, A.K., P.S. Brar, V.K. Singla, V.K. Gandotra, S. Nayyar and R. Jindal. 2009. Effect of handling different types of dystocia on minerals and biochemical profiles in dairy buffaloes. Vet. Pract. 10: 116-121.

- Singh, G., R.K. Chandolia, R. Dutt, A. Saini and R.K. Malik. 2018. Characteristics of middle uterine artery and umbilical blood flow in pregnant Murrah buffalo. Indian J. Anim. Reprod. 39(1): 11-14. https://doi.org/10.5455/ ijlr.20170426104230

- Srinivas, M., M. Sreenu, R.N. Lakshmi, N.K. Subramanyam and V. Deviprasad. 2007. Studies on dystocia in graded murrah buffaloes: a retrospective study. Buffalo Bull. 26: 40-45.

- Srinivasarao, N. 2016. Clinico-biochemical studies on uterine torsion in graded murrah buffaloes with special reference to its prognosis. M.V.Sc. Thesis. Dep. Vet. Gynaecol. Obstet. Sri Venkateswara Vet. Univ. Tirupati, India.

- Thangamani, A., M. Srinivas and B.C. Prasad. 2018a. Pathophysiological changes following uterine torsion in bovines- a review. Int. J. Pure Appl. Biosci. 6(2): 872-876. https://doi. org/10.18782/2320-7051.6448

- Thangamani, A., M. Srinivas, B.C. Prasad, K. Anusha, K.S. Rao and L.P. Kumar. 2018b. Unravelling the mystery of uterine torsion in Bovines: A review. Int. J. Sci., Environ. Technol. 7(2): 561-568.

- Tripathi, A. and J.S. Mehta. 2016. Studies on the types and prognostic approaches for uterine torsion among cattle. J. Anim. Res. 6(1): 129-134. https://doi.org/10.5958/2277940X.2016.00021.8

- Uttam, S., B. Singh, J.K. Chaudhary, S. Bassan, S. Kumar and N. Gupta. 2015. Analysis of morbidity and mortality rate in bovine under village conditions of Uttar Pradesh. Bioscan. 10(2): 585-591.

- Varughese, E.E., P.S. Brar and S.S. Dhindsa. 2013. Uterine blood flow during various stages of pregnancy in dairy buffaloes using transrectal Doppler ultrasonography. Anim. Reprod. Sci. 140: 34-39. https://doi.org/10.1016/j. anireprosci.2013.05.011

- Yadav, V., U. Singh, R.K. Chandolia, Devender and P. Kumar. 2015. Xylazine Sedation: A good help during rolling of buffaloes for correction of fresh uterine torsion. Haryana Vet. 54(2): 141143. 